\title{
Impact of the MTHFR C677T polymorphism on one-carbon metabolites: Evidence from a randomised trial of riboflavin supplementation
}

Rooney, M., Bottiglieri, T., Wasek-Patterson, B., McMahon, A., Hughes, C. F., McCann, A., Horigan, G., Strain, J. J., McNulty, H., \& Ward, M. (2020). Impact of the MTHFR C677T polymorphism on one-carbon metabolites: Evidence from a randomised trial of riboflavin supplementation. Biochimie, 173, 91-99.

https://doi.org/10.1016/j.biochi.2020.04.004

Link to publication record in Ulster University Research Portal

Published in:

Biochimie

Publication Status:

Published (in print/issue): 30/06/2020

DOI:

10.1016/j.biochi.2020.04.004

\section{Document Version}

Author Accepted version

\section{General rights}

Copyright for the publications made accessible via Ulster University's Research Portal is retained by the author(s) and / or other copyright owners and it is a condition of accessing these publications that users recognise and abide by the legal requirements associated with these rights.

\section{Take down policy}

The Research Portal is Ulster University's institutional repository that provides access to Ulster's research outputs. Every effort has been made to ensure that content in the Research Portal does not infringe any person's rights, or applicable UK laws. If you discover content in the Research Portal that you believe breaches copyright or violates any law, please contact pure-support@ulster.ac.uk. 


\section{Journal Pre-proof}

Impact of the MTHFR C677T polymorphism on one-carbon metabolites: Evidence from a randomised trial of riboflavin supplementation

Martina Rooney, Teodoro Bottiglieri, Brandi Wasek-Patterson, Amy McMahon, Catherine F. Hughes, Adrian McCann, Geraldine Horigan, J.J. Strain, Helene McNulty, Mary Ward

PII: S0300-9084(20)30074-2

DOI: https://doi.org/10.1016/j.biochi.2020.04.004

Reference: $\quad \mathrm{BIOCHI} 5866$

To appear in: Biochimie

Received Date: 8 November 2019

Revised Date: 4 April 2020

Accepted Date: 6 April 2020

Please cite this article as: M. Rooney, T. Bottiglieri, B. Wasek-Patterson, A. McMahon, C.F. Hughes, A. McCann, G. Horigan, J.J. Strain, H. McNulty, M. Ward, Impact of the MTHFR C677T polymorphism on one-carbon metabolites: Evidence from a randomised trial of riboflavin supplementation, Biochimie (2020), doi: https://doi.org/10.1016/j.biochi.2020.04.004.

This is a PDF file of an article that has undergone enhancements after acceptance, such as the addition of a cover page and metadata, and formatting for readability, but it is not yet the definitive version of record. This version will undergo additional copyediting, typesetting and review before it is published in its final form, but we are providing this version to give early visibility of the article. Please note that, during the production process, errors may be discovered which could affect the content, and all legal disclaimers that apply to the journal pertain.

(C) 2020 Published by Elsevier B.V. 
1 Impact of the MTHFR C677T polymorphism on one-carbon metabolites: evidence from

2 a randomised trial of riboflavin supplementation

3 Martina Rooney $^{\mathrm{a}}$, Teodoro Bottiglieri ${ }^{\mathrm{b}}$, Brandi Wasek-Patterson ${ }^{\mathrm{b}}$, Amy McMahon $^{\mathrm{a}}$, Catherine

4 F Hughes ${ }^{\mathrm{a}}$, Adrian McCann ${ }^{\mathrm{c}}$, Geraldine Horigan ${ }^{\mathrm{a}}$, JJ Strain ${ }^{\mathrm{a}}$, Helene McNulty ${ }^{\mathrm{a}}$, Mary Ward ${ }^{\mathrm{a}}$.

\section{Affiliations:}

6 a Nutrition Innovation Centre for Food and Health (NICHE), Ulster University, Cromore Rd,

7 Coleraine, BT55 1SA, Northern Ireland. ${ }^{\mathrm{b}}$ Center of Metabolomics, Institute of Metabolic

8 Disease, Baylor Scott \& White Research Institute, 3812 Elm St, Dallas, TX 75226, USA.

$9 \quad{ }^{\mathrm{c}}$ BEVITAL, Laboratoriebygget, 9 Etg, Jonas Lies Veg 87, 5021 Bergen, Norway

10 Email Addresses:

11 Martina Rooney: Rooney-m16@ulster.ac.uk; Teodoro Bottiglieri:

12 Teodoro.Bottiglieri@BSWHealth.org; Brandi Wasek-Patterson:

13 Brandi.WasekPatterson@BSWHealth.org; Amy McMahon: am2663@medschl.cam.ac.uk;

14 Catherine F Hughes: c.hughes@ulster.ac.uk; Adrian McCann: adrian.mccann@bevital.no;

15 Geraldine Horigan: gb.horigan@ulster.ac.uk; JJ Strain: jj.strain@ulster.ac.uk; Helene

16 McNulty: h.mcnulty@ulster.ac.uk; Mary Ward: mw.ward@ulster.ac.uk

17 Authors' last names: Rooney, Bottiglieri, Wasek-Patterson, McMahon, Hughes, McCann, 18 Horigan, Strain, McNulty, Ward.

19 Corresponding Author: Professor Mary Ward, Nutrition Innovation Centre for Food and Health (NICHE), School of Biomedical Sciences, Ulster University, Coleraine, Northern

21 Ireland, United Kingdom, BT52 1SA. Tel: +442870123076, E-mail: mw.ward@ulster.ac.uk 


\section{Highlights}

- The MTHFR 677TT genotype is associated with a $24-87 \%$ increased risk of hypertension

- Riboflavin (the precursor for the MTHFR cofactor, FAD), lowers BP in TT adults

- Perturbed one-carbon metabolism may influence the BP phenotype linked with TT genotype

- SAM concentrations and SAM:SAH ratio were lower in individuals with the TT genotype

- In the TT genotype group, SAM and cystathionine increased in response to riboflavin

\section{Key words}

MTHFR, riboflavin, S-adenosylmethionine, one-carbon metabolism, hypertension.

\section{Abbreviations}

5-MTHF, 5-methyltetrahydrofolate; ANOVA, analysis of variance; BHMT, betainehomocysteine methyltransferase; BP, blood pressure; CßS, cystathionine B-synthase; cv, coefficient of variation; CVD, cardiovascular disease; EGRac, estimated glutathione reductase activation coefficient; FAD, flavin adenine dinucleotide; GWAS, genome wide association study; HPLC-ESI-MS/MS, high-performance liquid chromatography; electrospray positive ionization tandem mass spectrometry; LC-MS/MS, liquid chromatography tandem mass spectrometry; MTHFR, methylenetetrahydrofolate reductase; NICHE, Nutrition Innovation Centre for Food and Health; NORCCAP; Norwegian Colorectal Cancer Prevention; PLP, pyridoxal-5'-phosphate; SAH, S-adenosylhomocysteine; 3 SAM, S-adenosylmethionine; SD, standard deviation. 
44 Abstract

45 Homozygosity for the C677T polymorphism in MTHFR (TT genotype) is associated with a $4624-87 \%$ increased risk of hypertension. Blood pressure (BP) lowering was previously 47 reported in adults with the TT genotype, in response to supplementation with the MTHFR 48 cofactor, riboflavin. Whether the BP phenotype associated with the polymorphism is related 49 to perturbed one-carbon metabolism is unknown. This study investigated one carbon metabolites and their responsiveness to riboflavin in adults with the TT genotype. Plasma samples from adults (n 115) screened for the MTHFR genotype, who previously participated in RCTs to lower BP, were analysed for methionine, S-adenosylmethionine (SAM), Sadenosylhomocysteine (SAH), betaine, choline and cystathionine by liquid chromatography tandem mass spectrometry (LC-MS/MS). The one-carbon metabolite response to riboflavin $(1.6 \mathrm{mg} / \mathrm{d} ; n$ 24) or placebo ( $n$ 23) for 16 weeks in adults with the TT genotype was also investigated. Plasma SAM (74.7 \pm 21.0 vs $85.2 \pm 22.6 \mathrm{nmol} / \mathrm{L}, \mathrm{P}=0.013)$ and SAM:SAH ratio $(1.66 \pm 0.55$ vs $1.85 \pm 0.51, \mathrm{P}=0.043)$ were lower and plasma homocysteine was higher $(\mathrm{P}=0.043)$ in $\mathrm{TT}$, compared to $\mathrm{CC}$ individuals. In response to riboflavin, $\mathrm{SAM}(\mathrm{P}=0.008)$ and cystathionine $(\mathrm{P}=0.045)$ concentrations increased, with no responses in other one-carbon metabolites. These findings confirm perturbed one-carbon metabolism in individuals with the MTHFR 677TT genotype, and for the first time demonstrate that SAM, and cystathionine, increase in response to riboflavin supplementation in this genotype group. The genotypespecific, one-carbon metabolite responses to riboflavin intervention observed could offer some insight into the role of this gene-nutrient interaction in blood pressure. 


\subsection{Introduction}

66

67

68

69

70

71

72

73

74

75

76

77

78

79

80

81

82

83

84

85

86

87

88

89

Hypertension is a major modifiable risk factor for stroke and cardiovascular disease (CVD), and a leading cause of premature mortality worldwide, responsible for over 10 million deaths annually [1]. The pathophysiology of hypertension is complex, involving the interaction of genetics, environmental factors and physiological mechanisms [2]. Genome wide association studies (GWAS) have linked a number of genetic loci with hypertension [3,4], including a region near the gene encoding the folate metabolising enzyme, methylenetetrahydrofolate reductase (MTHFR). The common MTHFR C677T polymorphism produces an enzyme with reduced activity [5] owing to lowered affinity for its riboflavin cofactor, (flavin adenine dinucleotide, FAD) [6]. The homozygous MTHFR 677TT genotype affects 2-32\% of populations worldwide [7] and meta-analyses have estimated that the variant TT genotype is associated with $24-87 \%$ increased risk of hypertension and increased risk for CVD by up to $40 \%$ [8]. Previous studies conducted at this Centre have demonstrated that BP is highly responsive to riboflavin supplementation, with evidence that systolic BP can be lowered by between 6 to $14 \mathrm{mmHg}$ in individuals with the TT genotype [9-11]. This gene-nutrient interaction thus offers a novel, nutritional approach for BP management among adults with the C677T variant in MTHFR, although the underlying mechanism remains unexplained. It is possible the phenotype of elevated $\mathrm{BP}$ and its response to riboflavin may be owing to perturbations in one-carbon metabolism in affected individuals; however, this mechanism has not been previously investigated.

In one-carbon metabolism, FAD-dependent MTHFR generates 5-methyltetrahydrofolate (5MTHF), which is involved in the remethylation of homocysteine to methionine, the precursor to S-adenosylmethionine (SAM; Figure 1). As the principal methyl donor, SAM transfers methyl groups to over 100 methyltransferases involved in numerous biochemical pathways including DNA methylation, histone modification and neurotransmitters [12]. This 
90 transfer, in turn, leads to the formation of S-adenosylhomocysteine (SAH), which is

91 subsequently metabolised to homocysteine. DNA methylation, an epigenetic process

92 involved in gene transcription and expression, has been implicated in a number of disease

93 states across the life-cycle, including CVD [13]. The ratio of SAM:SAH has been sometimes

94 used as a marker of methylation potential, although the validity of this indicator requires

95 confirmation [14]. Choline and betaine can also serve as alternative methyl donors in

96 homocysteine remethylation as part of the betaine-homocysteine methyltransferase (BHMT)

97 pathway [15]. Homocysteine can be removed through irreversible condensation with serine to

98 cystathionine via the action of cystathionine $\beta$-synthase (CßS), in the pyridoxal-5'-phosphate

99 (PLP)-dependent transsulfuration pathway. Regulation of the methylation cycle is essential to

100 ensure sufficient supply of SAM to methyltransferase reactions. This is achieved through the

101 action of SAM as an allosteric inhibitor of MTHFR and an allosteric activator of CßS, thus

102 controlling one-carbon flux and homocysteine levels [16].

103 Higher concentrations of SAM and SAH have been reported in TT relative to CC adults in 104 some [17,18] but not all [19,20] studies. In observational analysis of 10,601 Norwegian 105 adults elevated homocysteine and decreased betaine were reported in TT compared to CC 106 genotype groups, with no influence of genotype on other one-carbon metabolites [21-23].

107 Sub-optimal status of the B vitamins, folate, riboflavin, PLP and cobalamin, which act as 108 nutritional cofactors for the key enzymes in the one-carbon pathway (Figure 2), have been 109 previously shown to result in elevated homocysteine in adults generally and particularly by 110 MTHFR genotype [24,25]. The effect of intervention with one or a combination of these B 111 vitamins has been shown to modulate homocysteine concentrations [26-28]; however, the 112 effect on other one-carbon metabolites has not been widely investigated, and few studies have 113 considered the effect of the MTHFR 677TT genotype. 
114 Therefore, the aim of this study is to investigate the impact of the MTHFR C677T

115 polymorphism on one-carbon metabolite status and the responsiveness of one-carbon

116 metabolites to riboflavin supplementation $(1.6 \mathrm{mg} /$ day) in adults with the MTHFR 677TT

117 genotype. The findings of this study could contribute to our understanding of the mechanism

118 underpinning the BP phenotype related to this gene-nutrient interaction.

\section{$119 \quad 2.0$ Materials and Methods}

120

121

122

123

124

125

126

127

128

129

130

131

132

133

134

135

136

137

\subsection{Subjects and samples}

Plasma samples from participants who had previously participated in studies at the Nutrition Innovation Centre for Food and Health (NICHE), Ulster University, and had been screened for the MTHFR 677TT genotype were accessed for the current study. In all cases, participants provided informed, written consent and agreed for samples to be used in subsequent studies. Samples were accessed from the GENOVIT study (ORECNI ref 08/NIR03/40) [9], the GENOVIT follow-up study (ORECNI ref 08/NIR03/40) [10] and the RIBOGENE study (ORECNI/12/0338). Ethical approval for the analysis reported in the current study was granted by Ulster University Research Ethics Committee (FCBMS-18-040). All three studies had identical inclusion (pre-screened for MTHFR C677T polymorphism) and exclusion (history of gastrointestinal, hepatic or renal disease, consumers of B vitamin supplements, use of medication known to interfere with B vitamin metabolism) criteria. Clinic BP was measured in accordance with guidelines from the National Institute of Care and Excellence [29]. In brief, after ten minutes at rest, BP was measured in the reference arm, i.e. the arm with the highest $\mathrm{BP}$, with the participant in the seated position. Mean BP was calculated as the average of two BP readings within $5 \mathrm{mmHg}$, with a maximum of six readings obtained. Anthropometry, health and lifestyle information and blood samples were collected according to appropriate standardised operating procedures as part of each study, described in detail elsewhere $[9,10]$. 
138 The analysis for the current study consisted of both an observational and an intervention phase.

139 In the observational phase, participants with the TT genotype were age-matched with a similar

140 number of individuals with the CC genotype and compared for general characteristics and one-

141 carbon metabolite biomarker status. In the intervention phase, biomarker status of methionine,

142 SAM, SAH, SAM:SAH ratio, betaine, choline and cystathionine in response to intervention

143 with riboflavin ( $n$ 24) and placebo ( $n$ 23) were investigated (Figure 2).

\section{2.2. Blood sampling}

145 Venipuncture of a vein in the antecubital fossa was conducted by a trained phlebotomist with 146 the participant in a non-fasting state. A $25 \mathrm{ml}$ blood sample was obtained into two EDTA 147 vacutainers $(9 \mathrm{ml}$ and $4 \mathrm{ml})$ and two serum vacutainers $(8 \mathrm{ml}$ and $4 \mathrm{ml})$. All tubes, apart from the $1484 \mathrm{ml}$ EDTA tube, were placed immediately on ice and centrifuged at $3000 \mathrm{rpm}$ for 15 minutes at $1494^{\circ}$ Celsius, within 30 minutes of the venipuncture. Plasma, serum and buffy coat were removed 150 at this stage. The erythrocytes in the 9ml EDTA tube were thrice washed with phosphate 151 buffered saline and these washed red cells were used for erythrocyte glutathione reductase 152 activation coefficient (EGRac) analysis. The 4ml EDTA tube was rolled for 30 minutes, and $15350 \mu 1$ was added to $450 \mu 1$ of $1 \%$ ascorbic acid solution (1 in 10 dilution), from which red blood 154 cell folate was determined. All fractions were labelled and stored at $-80^{\circ}$ Celsius in alarm155 controlled freezers with batch analysis of biomarkers conducted at the end of the study. The 156 samples did not undergo any freeze-thaw cycles between initial storage and analysis.

\subsection{B vitamin biomarker analysis}

158 Riboflavin status was determined at Ulster University using the erythrocyte glutathione 159 reductase activation coefficient (EGRac) assay, which measures the enzyme activity of 160 glutathione reductase before and after in vitro reactivation with its prosthetic group FAD, as 
enzyme activity, with values $<1.3$ indicating optimal riboflavin status, 1.3-1.4 suboptimal status and $>1.4$ signifying deficiency. Red blood cell folate concentrations, a long-term biomarker of [31]. Plasma homocysteine was analysed by fluorescence polarisation immunoassay for plasma

167 homocysteine [32].

\subsection{Metabolite analysis}

169 One-carbon metabolites, apart from homocysteine, were analysed at the Center of 170 Metabolomics, Baylor Scott \& White Research Institute (Dallas, Texas 75226). Determination 171 of methionine, SAM, SAH, betaine, choline and cystathionine in plasma was performed by high

172 performance liquid chromatography coupled with electrospray positive ionization tandem mass 173 spectrometry (HPLC-ESI-MS/MS) using a method previously described with some minor 174 modification [33]. In brief, $20 \mu 1$ of plasma was added to $180 \mu 1$ of isotope internal standards and 175 loaded into a microtiter plate before being centrifuged for 60 minutes prior to analysis. The 176 calibration curve for SAM and SAH was 25-400-nmol/L, for methionine, betaine and choline; 177 3.1-50 nmol/L and for cystathionine: $125-2000 \mathrm{nmol} / \mathrm{L}$. Two levels of quality control samples 178 were used to monitor within and between day precision of the method. In all cases, the 179 coefficient of variation (cv) was less than $15 \%$ for all metabolites.

\section{$180 \quad 2.5$ Statistical analysis}

181 Statistical analyses were performed using Statistical Package for Social Sciences (SPSS;

182 version 25.0; SPSS UK Ltd, Chertsey, UK). Normality tests were carried out on the data and 183 data not normally distributed were log transformed before analysis was conducted. Differences 184 in general characteristics and one-carbon metabolite status between genotype groups 185 (observational cohort) were determined using independent samples t-test. Chi square test was 
186

187

188

189

190

191

192

193

194

195

196

197

198

199

200

201

202

203

204

205

206

$207 \mathrm{P}=0.043)$, lower SAM concentrations $(74.7 \pm 21.0$ vs $85.2 \pm 22.6 \mathrm{nmol} / \mathrm{L} \mathrm{P}=0.013)$ and lower

208 SAM:SAH ratio ( $1.66 \pm 0.55$ vs $1.85 \pm 0.51, \mathrm{P}=0.043)$ was observed in the TT compared to the

209 CC genotype (Table 2). No differences were observed for methionine, SAH, betaine, choline or

used for comparison between categorical variables. To determine the response to intervention,

within-between repeated-measures ANCOVA was used, controlling for baseline EGRac. The between-participant factor was the intervention group (placebo compared with riboflavin), and the within-participant factor was time (before compared with after intervention). Results are presented as mean (SD), unless otherwise stated. $\mathrm{P}<0.05$ was considered significant in all analysis carried out. Network analysis was performed with visualisation of the networks in a circular layout in corrplot and qgraph packages from R (version 3.3.0; R Core Team 2016, Vienna, Austria; www.R-project.org).

\subsection{Results}

Available plasma samples and data from adults ( $n$ 115) screened for the MTHFR genotype, and who previously participated in trials to lower BP were accessed. In the observational cohort, there were no significant differences in general characteristics between MTHFR genotype groups (Table 1). EGRac, the functional indicator of riboflavin status, was similar across the groups. PLP, serum and red blood cell folate concentrations were significantly lower in those with the TT compared to CC genotype. As previously reported, both systolic and diastolic BP were significantly elevated in the TT relative to CC genotype groups (mean difference $16.6 \pm$ $3.4 \mathrm{mmHg}, \mathrm{P}<0.001 ; 9.0 \pm 13.5 \mathrm{mmHg}, \mathrm{P}<0.001$, respectively), and those with the TT genotype were more likely to be classed as hypertensive according to current NICE guidelines [29]. There was no difference in use of anti-hypertensive medications between groups $(75 \%$ of $\mathrm{CC}$ and $83 \%$ of TT genotype, $\mathrm{P}=0.308)$.

In relation to one-carbon metabolites, elevated homocysteine $(10.4 \pm 3.0$ vs $9.3 \pm 2.5 \mu \mathrm{mol} / \mathrm{L}$ 
210 cystathionine by genotype group. Network analysis showed that the nature and strength of

211 interrelationships of metabolites and B vitamins within one-carbon metabolism were influenced

212 by MTHFR genotype (Figure 3).

Table 1

Characteristics of participants by MTHFR genotype (observational cohort $n$ 115)

\begin{tabular}{lccc}
\hline & MTHFR 677CC & MTHFR 677TT & \\
& $(\boldsymbol{n}$ 68) & $(\boldsymbol{n ~ 4 7 )}$ & value $^{\mathbf{1}}$ \\
\hline Age (years) & $54.7(6.0)$ & $54.3(6.0)$ & 0.807 \\
Male sex $n(\%)$ & $58(85)$ & $37(79)$ & 0.361 \\
BMI $\left(\mathrm{kg} / \mathrm{m}^{2}\right)$ & $29.1(4.9)$ & $29.1(4.6)$ & 0.956 \\
Diabetes mellitus $n(\%)$ & $8(12)$ & $5(11)$ & 0.851 \\
Smoker $n(\%)$ & $16(24)$ & $17(36)$ & 0.141 \\
Family history CVD $n(\%)$ & $31(46)$ & $34(72)$ & 0.229
\end{tabular}

$B$ vitamin biomarkers

Red blood cell folate (nmol/L) 1055 (557)

$809(385) \quad 0.045$

Serum folate $(\mathrm{nmol} / \mathrm{L})$

$12.2(8.0)$

$6.7(4.0)$

$<0.001$

PLP (nmol/L)

$72.0(38.3)$

$47.5(22.2)$

$<0.001$

EGRac (riboflavin status)

$1.37(0.18)$

$1.36(0.14)$

0.788

Blood Pressure

Systolic BP (mmHg)

$128.0(16.6)$

$144.7(19.2)$

$<0.001$

Diastolic BP (mmHg)

78.8 (11.9)

$87.1(12.4)$

$<0.001$

Pulse pressure $(\mathrm{mmHg})$

$49.3(12.4)$

$57.3(16.6)$

0.004

Hypertensive $^{2} n(\%)$

17 (25)

29 (62)

$<0.001$

BP medications $n(\%)$

$51(75)$

$39(83)$

0.308

Values are mean (SD). ${ }^{1} \mathrm{P}$ values refer to differences between genotype groups compared using independent samples t-test. Chi square test used for comparison between categorical variables. $\mathrm{P}<0.05$ considered significant. ${ }^{2}$ Hypertension defined as a $\mathrm{BP}$ reading of $\geq 140 \mathrm{mmHg}$ systolic and/or $\geq 90 \mathrm{mmHg}$ diastolic BP [31]. BP, blood pressure; CVD, cardiovascular disease; EGRac, erythrocyte glutathione reductase activation coefficient (a marker of riboflavin status where lower EGRac values indicate better riboflavin status); PLP, plasma-5'-pyridoxal phosphate. 
Table 2

One-carbon metabolites by MTHFR genotype (observational cohort $n$ 115)

MTHFR 677CC

MTHFR 677TT

$P$ value $^{1}$

(

( $n$ 47)

\begin{tabular}{lccc}
\hline Homocysteine $(\mu \mathrm{mol} / \mathrm{L})$ & $9.3(2.5)$ & $10.4(3.0)$ & 0.043 \\
Methionine $(\mu \mathrm{mol} / \mathrm{L})$ & $29.5(7.2)$ & $30.3(6.7)$ & 0.450 \\
SAM $(\mathrm{nmol} / \mathrm{L})$ & $85.2(22.6)$ & $74.7(21.0)$ & 0.013 \\
SAH $(\mathrm{nmol} / \mathrm{L})$ & $45.0(10.9)$ & $46.8(9.8)$ & 0.320 \\
SAM:SAH ratio & $1.85(0.51)$ & $1.66(0.55)$ & 0.043 \\
Betaine $(\mu \mathrm{mol} / \mathrm{L})$ & $53.1(13.7)$ & $50.5(15.8)$ & 0.194 \\
Choline $(\mu \mathrm{mol} / \mathrm{L})$ & $9.7(2.1)$ & $9.8(2.7)$ & 0.869 \\
Cystathionine $(\mathrm{nmol} / \mathrm{L})$ & $243(96)$ & $248(118)$ & 0.965
\end{tabular}

Values are mean (SD). ${ }^{1}$ Differences between genotype groups compared using independent ttests. SAM, S-adenosylmethionine; SAH, S-adenosylhomocysteine. $\mathrm{P}<0.05$ considered significant.

213 As previously reported [9-11], significant decreases were observed in both systolic $(-14.0 \pm$ $21415.3 \mathrm{mmHg}, \mathrm{P}=0.030)$ and diastolic $\mathrm{BP}(-8.2 \pm 11.1 \mathrm{mmHg}, \mathrm{P}=0.013)$ in response to riboflavin 215 supplementation which resulted in a significant decrease in EGRac $(-0.15 \pm 0.16, \mathrm{P}<0.001)$, 216 indicating improved riboflavin status, in those with the MTHFR 677TT genotype (Figure 4).

217 No change in red blood cell folate was observed (data not shown).

218 Response of one-carbon metabolites to riboflavin intervention among individuals with the TT 219 genotype in MTHFR is presented in Table 3. Plasma homocysteine decreased by $0.5 \pm 1.7$ $220 \mu \mathrm{mol} / \mathrm{L}$ in the riboflavin group, albeit an effect that was non-significant compared to the 221 placebo group. Mean plasma SAM concentration increased significantly in response to 222 riboflavin supplementation by $19.5 \pm 20.6(\mathrm{P}=0.021)$, where the nature of this effect was only 223 strengthened when adjusted for baseline riboflavin status $(\mathrm{P}=0.008)$. Plasma cystathionine 
224 concentrations increased by $50.7 \pm 92.5 \mathrm{nmol} / \mathrm{L}(\mathrm{P}=0.021)$, in response to riboflavin 225 supplementation. No other metabolites were affected by riboflavin intervention. 
Table 3

One-carbon metabolite response to riboflavin intervention in adults with the MTHFR 677TT genotype $(n$ 47)

\begin{tabular}{|c|c|c|c|c|c|c|}
\hline & \multicolumn{2}{|c|}{$\begin{array}{c}\text { Placebo } \\
\text { (n 23) }\end{array}$} & \multicolumn{2}{|c|}{$\begin{array}{l}\text { Riboflavin } \\
\text { (n 24) }\end{array}$} & \multicolumn{2}{|c|}{$P$ Value $^{1}$} \\
\hline & Pre & Post & Pre & Post & Model 1 & Model 2 \\
\hline Homocysteine $(\mu \mathrm{mol} / \mathrm{L})$ & $10.2(3.4)$ & $9.9(3.4)$ & $10.0(2.4)$ & $9.5(2.0)$ & 0.860 & 0.548 \\
\hline Methionine $(\mu \mathrm{mol} / \mathrm{L})$ & $29.4(5.7)$ & $29.5(6.6)$ & $30.5(7.0)$ & $33.8(10.0)$ & 0.213 & 0.310 \\
\hline $\mathrm{SAM}(\mathrm{nmol} / \mathrm{L})$ & $74.4(23.9)$ & $74.3(18.6)$ & $72.3(20.1)$ & $91.8(27.3)$ & 0.021 & 0.008 \\
\hline $\mathrm{SAH}$ (nmol/L) & $42.9(8.9)$ & $36.9(11.5)$ & $48.1(9.0)$ & $43.3(8.8)$ & 0.287 & 0.295 \\
\hline SAM:SAH ratio & $1.73(0.56)$ & $1.96(0.60)$ & $1.58(0.57)$ & $2.14(0.78)$ & 0.192 & 0.182 \\
\hline Betaine $(\mu \mathrm{mol} / \mathrm{L})$ & $46.7(16.1)$ & $48.2(15.9)$ & $51.6(15.5)$ & $53.9(18.0)$ & 0.854 & 0.777 \\
\hline Choline $(\mu \mathrm{mol} / \mathrm{L})$ & $9.3(2.7)$ & $9.3(2.5)$ & $10.0(2.61)$ & $10.0(2.9)$ & 0.642 & 0.816 \\
\hline Cystathionine (nmol/L) & $206(61)$ & $196(73)$ & $215(78)$ & $266(114)$ & 0.021 & 0.045 \\
\hline
\end{tabular}

Values presented as mean (SD). ${ }^{1} P$ value refers to time*treatment interaction (repeated measures ANOVA, comparing the effect of treatment vs placebo over time). Model 1: unadjusted, Model 2: adjusted for baseline EGRac. P<0.05 considered significant. SAM, S-adenosylmethionine; SAH, S-adenosylhomocysteine. 


\subsection{Discussion}

227 The findings of the current study report for the first time that that plasma concentrations of 228 the one-carbon metabolites, SAM and cystathionine, increase significantly in response to 229 riboflavin supplementation in individuals with the MTHFR C677T polymorphism. Coincident with this finding, we also observed lower concentrations of plasma SAM in TT compared to CC genotype adults. Indeed, after intervention with riboflavin in adults with the TT genotype, SAM concentrations increased to levels similar to those observed in adults with the CC genotype at baseline. The changes in plasma SAM and cystathionine concentrations in response to riboflavin intervention are consistent with the genotype specific BP response previously reported in response to supplementation with riboflavin, raising the possibility that the effect of this gene-nutrient interaction on BP may be influenced by the cofactor requirements.

To our knowledge, this is the first study to investigate the effect of intervention with riboflavin on SAM concentrations in adults with the MTHFR 677TT genotype. Previous investigations have, however, considered the effect of folic acid supplementation on onecarbon metabolites. In a small sub-group of MTHFR 677TT patients from the Verona Heart

242 Study Project, 5mg/d folic acid resulted in significant increases in SAM by 13nmol/L and 243 SAM:SAH ratio by 3.3, in addition to the expected reductions in homocysteine following 8 244 weeks of treatment [35]. The extent of the response in SAM of almost $20 \mathrm{nmol} / \mathrm{L}$ observed in the current study in response to riboflavin is even greater than these previous observations [35]. As the principal methyl donor, SAM-dependent methylation regulates fundamental

247 biological processes including nuclear transcription, cell signalling, mRNA translation and 248 DNA synthesis [12] and altered DNA methylation has previously been observed in TT 249 relative to CC adults [36]. Supplementing with B vitamins to regulate concentrations of SAM in adults with perturbed one-carbon metabolism owing to genetic variants, could thus 
251 potentially have important implications for CVD health outcomes. Previous studies have

252 linked methylation with hypertension; however, no one has considered the C677T

253 polymorphism in MTHFR or its relationship with SAM or BP. This is the first study to show

254 that riboflavin supplementation in those with the mutant genotype affects concentrations of

255 SAM and thus, possibly methylation potential. A recent meta-analysis reported lower global

256 methylation levels with higher systolic BP, diastolic BP and hypertension [37]. The same

257 meta-analysis also reported lower methylation levels of a number of candidate genes with

258 increased BP; however, MTHFR has not yet been considered to any great extent. While

259 hypertension was not considered in a meta-analysis by Amenyah et al., lower global

260 methylation was reported in those with the TT genotype in combination with low folate status

$261 \quad[38]$.

262 Choline and 5-MTHF are considered fungible methyl group sources in one-carbon

263 metabolism, and methyl groups from choline can also facilitate homocysteine remethylation

264 via the BHMT pathway [15]. In a study of folate-deficient males with the TT genotype,

265 intervention with $2,200 \mathrm{mg} /$ day choline over 12 weeks was found to significantly increase

266 plasma SAM concentrations compared to lower choline doses of 300-500 mg which were

267 associated with a decreased SAM concentration [18]. Whilst these studies investigated one-

268 carbon nutrients, BP was not considered. To date, research examining the effect of

269 supplementation with B vitamins on one-carbon metabolites in adults with the MTHFR

270 677TT genotype has predominantly focused on the established phenotype of elevated

271 homocysteine. Numerous meta-analyses demonstrating the responsiveness of homocysteine

272 to supplementation with a combination of B vitamins have been published [24,25,39];

273 however, other one-carbon metabolites apart from homocysteine have received little attention

274 in studies of this nature. Studies at our Centre have previously reported that riboflavin 
275 supplementation lowers homocysteine in TT, but not CC, individuals, although, the response 276 of other one-carbon metabolies were not considered $[9,26]$.

277 Plasma cystathionine significantly increased in response to riboflavin supplementation in the 278 current analysis. It is possible that increased availability of SAM, an allosteric regulator of 279 cystathionine $\beta$-synthase (CßS), in response to riboflavin may potentially have activated CBS, thereby increasing homocysteine elimination from the one-carbon pathway and generating cystathionine [16]. In addition, riboflavin administered at the same dose as the current study (1.6 mg/day) has previously been found to improve PLP status in older adults [40] and may thus augment the activity of PLP-dependent CBS. Consistent with earlier findings reported by Midttun and colleagues [23] lower PLP concentrations were observed in the current study in participants with the TT genotype. Those with the MTHFR 677TT genotype have reduced affinity for their riboflavin cofactor, FAD [6], thus are likely to have an increased requirement for riboflavin. Considering that cells appear to have a tendency to spare FAD at the expense of FMN [41] it is possible that FMN-dependent pathways (such as the pathway required to convert vitamin B6 into active PLP) may be compromised in those with the mutant genotype, leading to reduced vitamin B6 metabolism and thus lower PLP concentrations.

292 A paucity of evidence exists with respect to investigating the impact of MTHFR genotype on 293 SAM and SAH concentrations. In a cohort of Mexican-American males, Shin et al., reported increased concentrations of SAH and decreased SAM:SAH ratio in those with the TT compared to the CC genotype [18]. Davis et al., observed elevated SAM in young females with the TT relative to CC genotype; however this was not significant [17]. This is in contrast with the findings of the current analysis, where decreased SAM was observed in the TT compared to $\mathrm{CC}$ genotype group. Increased transmethylation reaction flux (i.e. conversion of SAM to SAH) has been found in females with the TT compared to the CC genotype [42]. A 
number of studies have found that the TT genotype is not a determinant of SAM or SAH

$[17,43]$ but folate status appears to be an important modulator of this effect [20]. Pertubations

in one-carbon metabolism can impair the synthesis of SAM, and potentially lead to epigenetic

alerations (specifically aberrant DNA methylation); correspondingly global DNA

\section{4}

hypomethylation has been previously reported in individuals with the TT compared to CC genotype $[44,45]$. The ratio of SAM:SAH has been proposed by some as an indicator of methylation potential, although confirmation of its validity remains to be established.

Methylation regulation enzymes are differentially expressed in human tissues, leading to

SAM:SAH ratio is not necessarily a meaningful indicator of methylation potential in all

310 tissues [14]. In the current analysis, lower SAM:SAH ratio was observed in the TT compared to $\mathrm{CC}$ genotype group, driven by the reduced SAM concentrations. However, these results are

312 at odds with another study that reported the MTHFR genotype did not influence the ratio of 313 SAM:SAH [43].

314 The observational results of the current analysis are broadly in agreement with those of the

315 Norwegian Colorectal Cancer Prevention (NORCCAP) study, where differences in one316 carbon metabolite status in individuals with the TT relative to the CC genotype were reported 317 in 10,601 adults aged 50-64 years [21-23]. In agreement with our baseline analysis, these 318 studies also reported the expected phenotype of elevated homocysteine, lower folate and 319 lower PLP concentrations in the TT compared to the CC genotype. No MTHFR genotype 320 effect was noted in relation to methionine, choline and cystathionine. One notable difference 321 in the observed associations reported in the Norwegian cohort compared to the current cohort 322 is betaine, where concentrations among Norwegians were significantly lower in those with 323 the TT genotype compared to non-TT genotypes [22]. Betaine has been suggested as a 
preferential methyl donor in TT males relative to CC males [46]; however, in our analysis no

325

326

327

328

329

330

331

332

333

334

335

336

337

338

339

340

341

342

343

344

345

346

347 genotype effect was noted with respect to betaine.

\subsection{Strengths and limitations}

This is the first study to consider the effect of the MTHFR cofactor, riboflavin, on one-carbon metabolites in adults stratified by MTHFR genotype. Samples from a number of carefully conducted randomised controlled trials utilising identical dose, duration and study protocols were accessed. The one-carbon metabolite analysis, which is known to pose analytical challenges, was conducted at a Centre with considerable expertise in laboratory analysis of one-carbon metabolite biomarkers. Furthermore, EGRac is considered the gold standard method for measurement of long-term riboflavin status and this measure was available for all participants. One limitation of the current study is the relatively small sample size which may have limited the ability to detect small differences in certain metabolites either between genotypes or in response to riboflavin. Additional biomarker information, in particular 5MTHF, which is generated by the MTHFR enzyme, might further add to our understanding of the role of this gene-nutrient interaction in BP regulation. The intervention could also be extended to those with MTHFR 677CC genotype.

\subsection{Conclusion}

In conclusion, this study shows evidence of perturbed one-carbon metabolism in individuals with the MTHFR C677T polymorphism, in particular reduced concentrations of the principal methyl donor, SAM. This study provides the first evidence that altered one-carbon flux may be alleviated through riboflavin supplementation in individuals with the C677T variant in MTHFR. The findings of this study may shed some light on the mechanism underpinning the elevated BP phenotype related to this gene-nutrient interaction, which, in turn could influence health outcomes in adult cohorts. Future studies investigating the effect of riboflavin and 
348 other B vitamins on one-carbon metabolite concentrations, are needed to further explore the

349 potential mechanisms underlying the effect of this gene-nutrient interaction on BP among

350 individuals with the MTHFR 677TT genotype.

\section{Acknowledgements}

352 The authors would like to acknowledge Dr Aoife Caffrey for research input.

\section{$353 \quad$ Funding sources}

354 This was supported by GRO-UR-Networks funding from Ulster University to cover travel for 355 MR to the Center of Metabolomics, Baylor Scott \& White Research Institute in Dallas for 356 sample analysis. The PhD studentship for MR was funded by the Vice Chancellors Research 357 Scholarship at Ulster University. DSM provided part support for the RIBOGENE study but 358 were not involved in the design, implementation, analysis, or interpretation of the data.

\section{Contributors}

360 MR, TB and BWP conducted the analysis. GH and AMcM collected the original samples 361 under the supervision of $\mathrm{CH}, \mathrm{MW}, \mathrm{HMcN}$ and JJS. MR analysed the data. AMcC conducted 362 network analysis. MR wrote the initial draft of the manuscript with critical input from MW and $\mathrm{HMcN}$. MW and $\mathrm{HMcN}$ had primary responsibility for the final content and all authors provided important revisions. All authors read and approved the final manuscript. 


\section{References}

365 [1] J.D. Stanaway, A. Afshin, E. Gakidou, et al., Global, regional, and national comparative risk assessment of 84 behavioural, environmental and occupational, and metabolic risks or clusters of risks for 195 countries and territories, 1990-2017: A systematic analysis for the Global Burden of Disease Stu, Lancet. (2018) 1923-1994. https://doi.org/10.1016/S0140-6736(18)32225-6.

[2] R.S. Patel, S. Masi, S. Taddei, Understanding the role of genetics in hypertension, Eur. Heart J. 38 (2017) 2309-2312. https://doi.org/10.1093/eurheartj/ehx273.

372 [3] C. Newton-Cheh, T. Johnson, V. Gateva, et al, Genome-wide association study identifies eight loci associated with blood pressure, Nat. Genet. 41 (2009) 666-676. https://doi.org/10.1038/ng.361.

[4] M.J. Flister, S.-W. Tsaih, C.C. O’Meara, B. Endres, M.J. Hoffman, A.M. Geurts, M.R. Dwinell, J. Lazar, H.J. Jacob, C. Moreno, Identifying multiple causative genes at a single GWAS locus., Genome Res. 23 (2013) 1996-2002. https://doi.org/10.1101/gr.160283.113. 
disease: a common mutation in methylenetetrahydrofolate reductase., Nat. Genet. 10 (1995) 111-3. https://doi.org/10.1038/ng0595-111.

382

[6] K. Yamada, Z. Chen, R. Rozen, R.G. Matthews, Effects of common polymorphisms on the properties of recombinant human methylenetetrahydrofolate reductase, Proc. Natl. Acad. Sci. U. S. A. 98 (2001) 14853-14858. https://doi.org/10.1073/pnas.261469998.

[7] B. Wilcken, F. Bamforth, Z. Li, E. Al., Geographical and ethnic variation of the 677C > T allele of 5,10 methylenetetrahydrofolate reductase, J MedGenet. 40 (2003) $619-625$.

[8] H. McNulty, J.J. Strain, C.F. Hughes, M. Ward, Riboflavin, MTHFR genotype and blood pressure: A personalized approach to prevention and treatment of hypertension, Mol. Aspects Med. 53 (2017) 2-9. https://doi.org/10.1016/j.mam.2016.10.002.

[9] G. Horigan, H. McNulty, M. Ward, J.J.J. Strain, J. Purvis, J.M. Scott, Riboflavin lowers blood pressure in cardiovascular disease patients homozygous for the $677 \mathrm{C} \rightarrow \mathrm{T}$ polymorphism in MTHFR, J. Hypertens. 28 (2010) 478-486. https://doi.org/10.1097/HJH.0b013e328334c126.

[10] C.P. Wilson, M. Ward, H. McNulty, J.J. Strain, T.G. Trouton, G. Horigan, J. Purvis, J.M. Scott, Riboflavin offers a targeted strategy for managing hypertension in patients with the MTHFR 677TT genotype: A 4-y follow-up, Am. J. Clin. Nutr. 95 (2012) 766-772. https://doi.org/10.3945/ajcn.111.026245.

[11] C.P. Wilson, H. McNulty, M. Ward, J.J. Strain, T.G. Trouton, B.A. Hoeft, P. Weber, F.F. Roos, G. Horigan, L. McAnena, J.M. Scott, Blood pressure in treated hypertensive individuals with the MTHFR 677TT genotype is responsive to intervention with riboflavin: Findings of a targeted randomized trial, Hypertension. 61 (2013) 1302- 
1308. https://doi.org/10.1161/HYPERTENSIONAHA.111.01047.

405

406

407

408

409

410

411

412

413

414

415

416

417

418

419

420

421

422

423

424

425

426

[12] L.B. Bailey, P.J. Stover, H. McNulty, E. Al., Biomarkers of Nutrition for Development—Folate Review, J. Nutr. 145 (2015) 1636S-1680S. https://doi.org/10.3945/jn.114.206599.

[13] H. McNulty, M. Ward, L. Hoey, C.F. Hughes, K. Pentieva, Addressing optimal folate and related B-vitamin status through the lifecycle: health impacts and challenges, Proc. Nutr. Soc. 78 (2019) 449-462. https://doi.org/10.1017/S0029665119000661.

[14] P. Dominguez-Salas, S.E. Cox, A.M. Prentice, B.J. Hennig, S.E. Moore, Maternal nutritional status, C 1 metabolism and offspring DNA methylation: A review of current evidence in human subjects, in: Proc. Nutr. Soc., 2012: pp. 154-165. https://doi.org/10.1017/S0029665111003338.

[15] M.D. Niculescu, S.H. Zeisel, Diet, Methyl Donors and DNA Methylation: Interactions between Dietary Folate, Methionine and Choline, J. Nutr. 132 (2002) 2333S-2335S. https://doi.org/10.1093/jn/132.8.2333S.

[16] J.M. Scott, D.G. Weir, Folic acid, homocysteine and one-carbon metabolism: a review of the essential biochemistry., J. Cardiovasc. Risk. 5 (1998) 223-7. http://www.ncbi.nlm.nih.gov/pubmed/9919469 (accessed August 9, 2019).

[17] S.R. Davis, E.P. Quinlivan, K.P. Shelnutt, D.R. Maneval, H. Ghandour, A. Capdevila, B.S. Coats, C. Wagner, J. Selhub, L.B. Bailey, J.J. Shuster, P.W. Stacpoole, J.F. Gregory, The Methylenetetrahydrofolate Reductase $677 \mathrm{C} \rightarrow$ T Polymorphism and Dietary Folate Restriction Affect Plasma One-Carbon Metabolites and Red Blood Cell Folate Concentrations and Distribution in Women, J. Nutr. 135 (2005) 1040-1044. https://doi.org/10.1093/jn/135.5.1040. 
[18] W. Shin, J. Yan, C.M. Abratte, F. Vermeylen, M.A. Caudill, Choline intake exceeding current dietary recommendations preserves markers of cellular methylation in a genetic subgroup of folate-compromised men., J. Nutr. 140 (2010) 975-80. https://doi.org/10.3945/jn.110.121186.

[19] F.R. Lopreato, S.P. Stabler, F.R. Carvalho, R.D.C. Hirata, M.H. Hirata, D.L. Robi, L.F. Sampaio-Neto, R.H. Allen, E.M. Guerra-Shinohara, Relationships between gene polymorphisms of folate-related proteins and vitamins and metabolites in pregnant women and neonates, Clin. Chim. Acta. 398 (2008) 134-139. https://doi.org/10.1016/J.CCA.2008.09.004.

[20] V. Ho, T.E. Massey, W.D. King, Effects of methionine synthase and methylenetetrahydrofolate reductase gene polymorphisms on markers of one-carbon metabolism, Genes Nutr. 8 (2013) 571-580. https://doi.org/10.1007/s12263-013-03582.

[21] S. Hustad, Ø. Midttun, J. Schneede, S.E. Vollset, T. Grotmol, P.M. Ueland, The Methylenetetrahydrofolate Reductase $677 \mathrm{C} \rightarrow$ T Polymorphism as a Modulator of a B Vitamin Network with Major Effects on Homocysteine Metabolism, Am. J. Hum. Genet. 80 (2007) 846-855. https://doi.org/10.1086/513520.

[22] P.I. Holm, S. Hustad, P.M. Ueland, S.E. Vollset, T. Grotmol, J. Schneede, Modulation of the Homocysteine-Betaine Relationship by Methylenetetrahydrofolate Reductase 677 C-\&gt;T Genotypes and B-Vitamin Status in a Large-Scale Epidemiological Study, J. Clin. Endocrinol. Metab. 92 (2007) 1535-1541. https://doi.org/10.1210/jc.2006-1471.

[23] Ø. Midttun, S. Hustad, J. Schneede, S.E. Vollset, P.M. Ueland, Plasma vitamin B-6 forms and their relation to transsulfuration metabolites in a large, population-based 
study, Am. J. Clin. Nutr. 86 (2007) 131-138. https://doi.org/10.1093/ajcn/86.1.131.

452

453

454

455

456

457

458

459

460

461

462

463

464

465

466

467

468

469

470

471

472

473

474

[24] R. Clarke, L. Brattström, F. Landgren, B. Israelsson, A. Lindgren, B. Hultberg, A. Andersson, G. Cuskelly, H. McNulty, S.S. Strain, J. McPartlin, D.G. Weir, J.M. Scott, H. den Heijer, I.A. Brouwer, H.J. Blom, G.M.J. Bos, A. Spaans, F.R. Rosendaal, C.M.G. Thomas, H.L. Haak, P.W. Wijermans, W.B.J. Gerrits, H.J. Naurath, E. Joosten, R. Riezler, S.P. Stabler, R.H. Allen, J. Lindenbaum, K. Pietrzik, R. Prinz-Langenohl, J. Dierkes, E. Saltz-man, J.B. Mason, P. Jacques, J. Selhub, D. Salem, E. Schaefer, I.H. Rosenberg, J. Ubbink, A. van der Mere, W.J.H. Vermack, R. Delport, P.J. Becker, H.C. Potgieter, J. V. Woodside, J.W.G. Yarnell, D. McMaster, I.S. Young, E.E. McCrum, S.S. Patterson, K.F. Gey, A.E. Evans, P. Appleby, P. Harding, P. Sherliker, R. Collins, C. Frost, V. Leroy, Lowering blood homocysteine with folic acid based supplements: Meta-analysis of randomised trials, Br. Med. J. 316 (1998) 894-898. https://doi.org/10.1136/bmj.316.7135.894.

[25] R. Clarke, C. Frost, P. Sherliker, E. Al., Dose-dependent effects of folic acid on blood concentrations of homocysteine: A meta-analysis of the randomized trials, Am. J. Clin. Nutr. 82 (2005) 806-812. https://doi.org/10.1093/ajcn/82.4.806.

[26] H. McNulty, L.R.C. Dowey, J.J. Strain, A. Dunne, M. Ward, A.M. Molloy, L.B. McAnena, J.P. Hughes, M. Hannon-Fletcher, J.M. Scott, Riboflavin lowers homocysteine in individuals homozygous for the MTHFR $677 \mathrm{C} \rightarrow \mathrm{T}$ polymorphism, Circulation. 113 (2006) 74-80. https://doi.org/10.1161/CIRCULATIONAHA.105.580332.

[27] Y. Lamers, R. Prinz-Langenohl, R. Moser, K. Pietrzik, Supplementation with [6S]-5methyltetrahydrofolate or folic acid equally reduces plasma total homocysteine concentrations in healthy women, Am. J. Clin. Nutr. 79 (2004) 473-478. 
https://doi.org/10.1093/ajcn/79.3.473.

476

477

478

479

480

481

482

483

484

485

486

487

488

489

490

491

492

493

494

495

496

497

[28] K.S. Crider, J.H. Zhu, L. Hao, Q.H. Yang, T.P. Yang, J. Gindler, D.R. Maneval, E.P. Quinlivan, Z. Li, L.B. Bailey, R.J. Berry, MTHFR 677C $\rightarrow$ T genotype is associated with folate and homocysteine concentrations in a large, population-based, double-blind trial of folic acid supplementation, Am. J. Clin. Nutr. 93 (2011) 1365-1372. https://doi.org/10.3945/ajcn.110.004671.

[29] N. National Institute for Health and Care Excellence, Hypertension in adults: diagnosis and management CG127, (2011). https://www.nice.org.uk/guidance/cg127 (accessed October 30, 2019).

[30] A.M. Molloy, J.M. Scott, Microbiological assay for serum, plasma, and red cell folate using cryopreserved, microtiter plate method, Methods Enzymol. 281 (1997) 43-53. https://doi.org/10.1016/S0076-6879(97)81007-5.

[31] C.J. Bates, K.D. Pentieva, A. Prentice, M.A. Mansoor, S. Finch, Plasma pyridoxal phosphate and pyridoxic acid and their relationship to plasma homocysteine in a representative sample of British men and women aged 65 years and over, Br. J. Nutr. 81 (1999) 191-201. https://doi.org/10.1017/S0007114599000380.

[32] A. Leino, Fully automated measurement of total homocysteine in plasma and serum on the Abbott IMx analyzer, Clin. Chem. 45 (1999) 569 -571.

[33] E. Arning, T. Bottiglieri, Quantitation of S-Adenosylmethionine and SAdenosylhomocysteine in Plasma Using Liquid Chromatography-Electrospray Tandem Mass Spectrometry, in: Clin. Appl. Mass Spectrom. Biomol. Anal., Humana Press, New York, 2016: pp. 255-262. https://doi.org/10.1007/978-1-4939-3182-8.

[34] National Institute for Health and Care Excellence (NICE), Hypertension in adults: 
diagnosis and management NG136, NICE, 2019. https://www.nice.org.uk/guidance/ng136 (accessed September 6, 2019).

500

501

502

503

504

505

506

507

508

509

510

511

512

513

514

515

516

517

518

519

520

[35] F. Pizzolo, H.J. Blom, S.W. Choi, D. Girelli, P. Guarini, N. Martinelli, A. Maria Stanzial, R. Corrocher, O. Olivieri, S. Friso, Folic Acid Effects on SAdenosylmethionine, S-Adenosylhomocysteine, and DNA Methylation in Patients with Intermediate Hyperhomocysteinemia, J. Am. Coll. Nutr. 30 (2011) 11-18. https://doi.org/10.1080/07315724.2011.10719939.

[36] S. Friso, S.-W. Choi, D. Girelli, J.B. Mason, G.G. Dolnikowski, P.J. Bagley, O. Olivieri, P.F. Jacques, I.H. Rosenberg, R. Corrocher, J. Selhub, A common mutation in the 5,10-methylenetetra-hydrofolate reductase gene affects genomic DNA methylation through an interaction with folate status, n.d. www.pnas.orgcgidoi10.1073pnas.062066299 (accessed November 1, 2019).

[37] V. Gonzalez-Jaramillo, E. Portilla-Fernandez, M. Glisic, T. Voortman, W. Bramer, R. Chowdhury, A.J.M. Roks, A.H. Jan Danser, T. Muka, J. Nano, O.H. Franco, The role of DNA methylation and histone modifications in blood pressure: a systematic review, J. Hum. Hypertens. 33 (2019) 703-715. https://doi.org/10.1038/s41371-019-0218-7.

[38] S.D. Amenyah, C.F. Hughes, M. Ward, S. Rosborough, J. Deane, S.-J. Thursby, C.P. Walsh, D.E. Kok, J.J. Strain, H. McNulty, D.J. Lees-Murdock, Influence of nutrients involved in one-carbon metabolism on DNA methylation in adults-a systematic review and meta-analysis, Nutr. Rev. (2020). https://doi.org/10.1093/nutrit/nuz094.

[39] C.P. Wilson, H. Mcnulty, J.M. Scott, J.J. Strain, M. Ward, The MTHFR C677T polymorphism, B-vitamins and blood pressure, Proc. Nutr. Soc. 69 (2009) 156-165. https://doi.org/10.1017/S0029665109991728. 
522

523

524

525

526

527

528

529

530

531

532

533

534

535

536

537

538

539

540

541

542

543

544

545

Strain, Riboflavin and vitamin B-6 intakes and status and biochemical response to riboflavin supplementation in free-living elderly people, Am. J. Clin. Nutr. 68 (1998) 389-395. https://doi.org/10.1093/ajcn/68.2.389.

[41] S. Fass, R.S. Rivlin, Regulation of riboflavin-metabolizing enzymes in riboflavin deficiency, 1969. http://ajplegacy.physiology.org/ (accessed August 6, 2019).

[42] S.R. Davis, E.P. Quinlivan, K.P. Shelnutt, H. Ghandour, A. Capdevila, B.S. Coats, C. Wagner, B. Shane, J. Selhub, L.B. Bailey, J.J. Shuster, P.W. Stacpoole, J.F. Gregory, Homocysteine Synthesis Is Elevated but Total Remethylation Is Unchanged by the Methylenetetrahydrofolate Reductase $677 \mathrm{C} \rightarrow \mathrm{T}$ Polymorphism and by Dietary Folate Restriction in Young Women, J. Nutr. 135 (2005) 1045-1050. https://doi.org/10.1093/jn/135.5.1045.

[43] L.M.J.W. van Driel, M.J.C. Eijkemans, R. de Jonge, J.H.M. de Vries, J.B.J. van Meurs, E.A.P. Steegers, R.P.M. Steegers-Theunissen, Body Mass Index Is an Important Determinant of Methylation Biomarkers in Women of Reproductive Ages, J. Nutr. 139 (2009) 2315-2321. https://doi.org/10.3945/jn.109.109710.

[44] R. Castro, I. Rivera, P. Ravasco, M.E. Camilo, C. Jakobs, H.J. Blom, I.T. de Almeida, methylenetetrahydrofolate reductase (MTHFR) 677CRT and 1298ARC mutations are associated with DNA hypomethylation, J Med Genet. 41 (2004) 454-458. https://doi.org/10.1136/jmg.2003.017244.

[45] A.S. Weiner, U.A. Boyarskikh, E.N. Voronina, O. V. Mishukova, M.L. Filipenko, Methylenetetrahydrofolate reductase C677T and methionine synthase A2756G polymorphisms influence on leukocyte genomic DNA methylation level, Gene. 533 (2014) 168-172. https://doi.org/10.1016/j.gene.2013.09.098.

[46] J. Yan, W. Wang, J.F. Gregory, O. Malysheva, J.T. Brenna, S.P. Stabler, R.H. Allen, 
M.A. Caudill, MTHFR C677T genotype influences the isotopic enrichment of onecarbon metabolites in folate-compromised men consuming d9-choline, Am. J. Clin. Nutr. 93 (2011) 348-355. https://doi.org/10.3945/ajcn.110.005975.

549

550

[47] P. James, S. Sajjadi, A.S. Tomar, A. Saffari, C.H.D. Fall, A.M. Prentice, S. Shrestha, P. Issarapu, D.K. Yadav, L. Kaur, K. Lillycrop, M. Silver, G.R. Chandak, Candidate genes linking maternal nutrient exposure to offspring health via DNA methylation: A review of existing evidence in humans with specific focus on one-carbon metabolism, Int. J. Epidemiol. 47 (2018) 1910-1937. https://doi.org/10.1093/ije/dyy153.

\section{Figure legends}

Figure 1. Overview of one-carbon metabolism. Abbreviations: BHMT, betainehomocysteine methyltransferase; $\mathrm{C} \beta \mathrm{S}$, cystathionine- $\beta$-synthase; $\mathrm{CTH}$, cystathionine $\gamma$-lyase; DHFR, dihydrofolate reductase; dTMP, deoxythymidine monophosphate; dUMP, deoxyuridine monophosphate; FAD, flavin adenine dinucleotide; GNMT, glycine Nmethyltransferase; MAT, methionine adenosyltransferase; MS, methionine synthase; MT, methyltransferases; MTHFR, methylenetetrahydrofolate reductase; MTHFD, methylenetetrahydrofolate dehydrogenase; SAHH, S-adenosyl homocysteine hydrolase; SHMT, serine hydroxymethyltransferase; TS, thymidylate synthase. Adapted from James et al. [47].

Figure 2. Flow diagram of study population. ${ }^{1} \mathrm{CC}$ (wild type) and TT (homozygous) genotypes for the MTHFR C677T polymorphism.

Figure 3. Network analysis to show interrelationships within one-carbon metabolism by MTHFR genotype group: CC, panel a; TT, panel b. Positive and inverse associations 
indicated by green and red edges, respectively. Strength of association indicated by edge thickness. Abbreviations: Smk, smoking; SBP, systolic blood pressure; BMI, body mass index; Met, methionine; HCY, homocysteine; Cys, cystathionine; SAM, Sadenosylmethionine; SAH, S-adenosylhomocysteine; SSr, SAM:SAH ratio; Cho, choline; Bet, betaine; B2, riboflavin; PLP, Pyridoxal-5'-phosphate; RCF, red blood cell folate.

Figure 4. Change in riboflavin biomarker (panel a), systolic BP (panel b), and diastolic BP (panel c) in response to supplementation with placebo or riboflavin $(1.6 \mathrm{mg} / \mathrm{d})$ for 16 weeks. For riboflavin biomarker, a decrease in EGRac indicates an improvement in riboflavin status. 


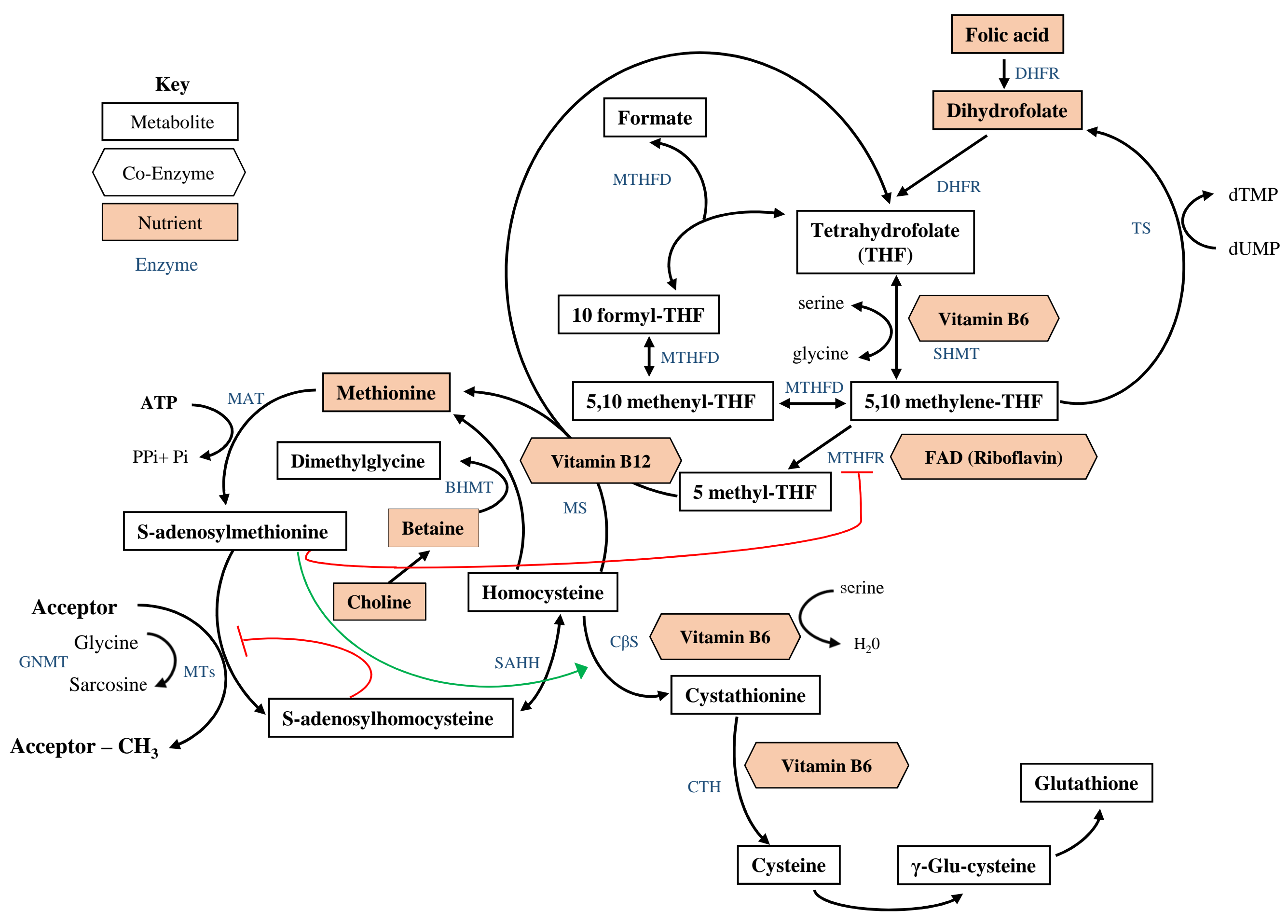




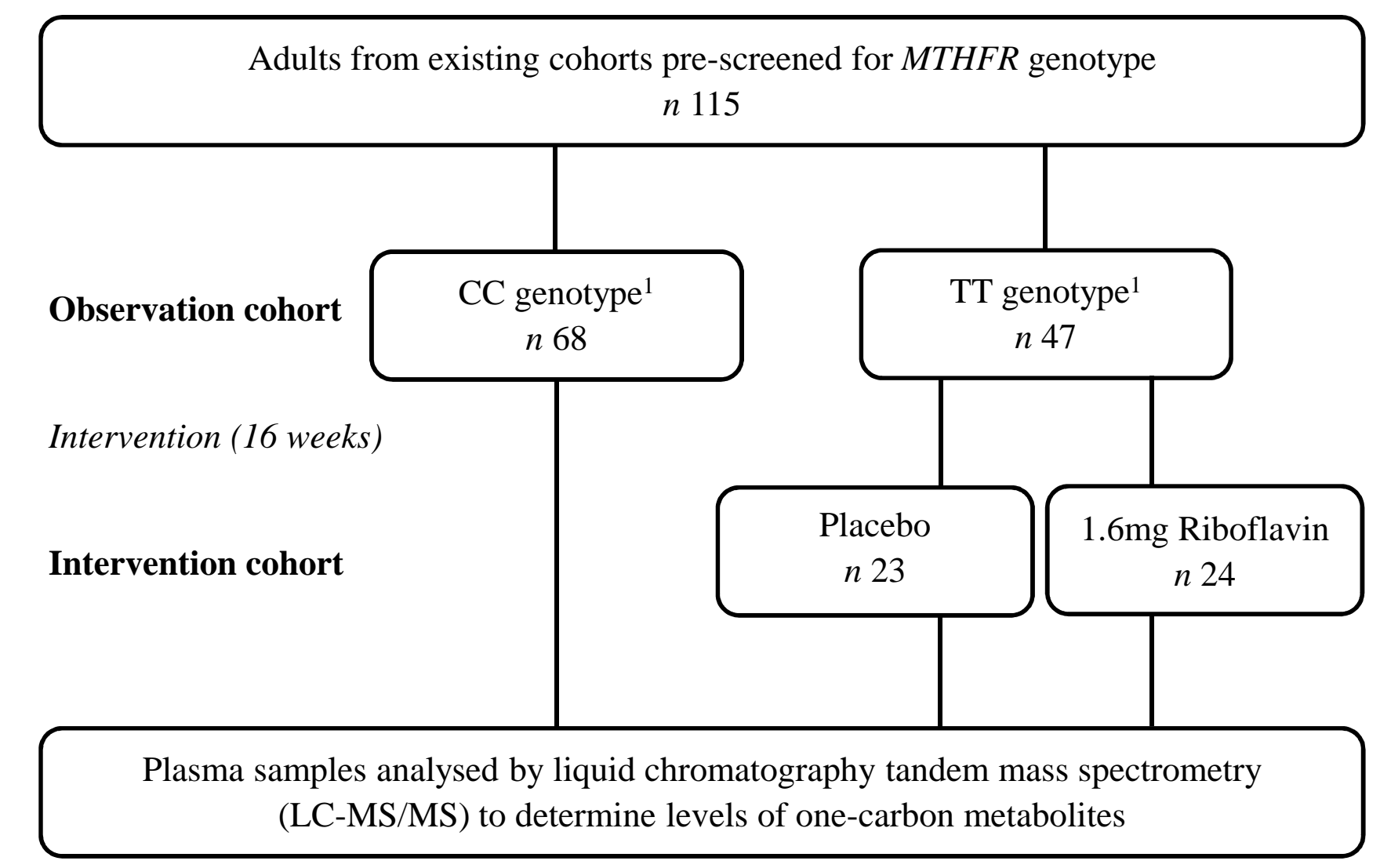



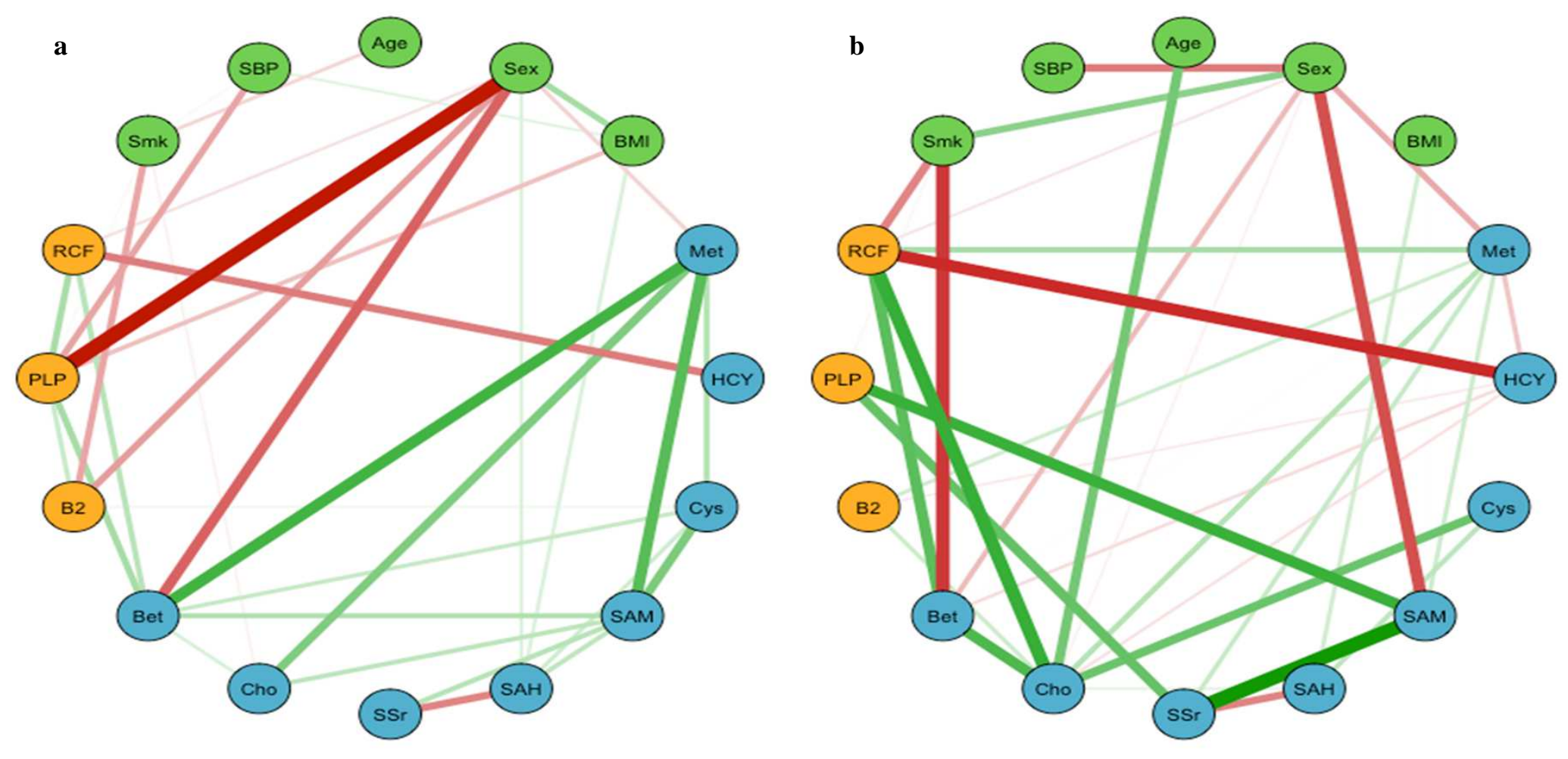

Participant characteristics

One-carbon metabolites

B vitamins 


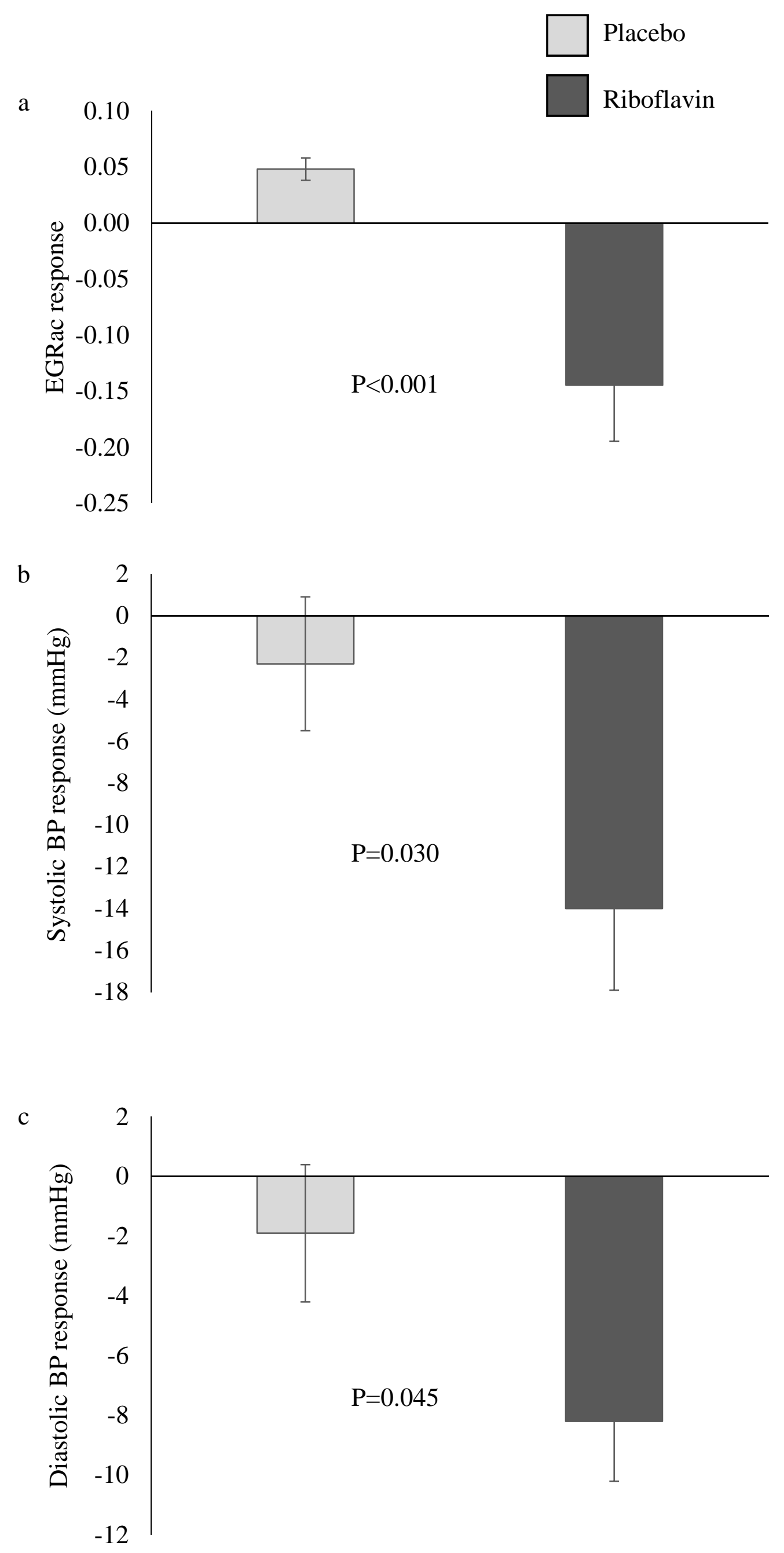

